ISSN 0258-7122

Bangladesh J. Agril. Res. 39(4): 553-561, December 2014

\title{
MULTIVARIATE ANALYSIS IN YELLOW INBRED LINES OF MAIZE (Zea mays L.)
}

\author{
M. AMIRUZZAMAN ${ }^{1}$, M. N. AMIN ${ }^{2}$, M. QUADIR ${ }^{3}$ AND M. H. RASHID ${ }^{4}$
}

\begin{abstract}
Twenty five yellow inbred lines of normal maize were evaluated for eleven parameters to study the genetic divergence using Mahalonabis's $\mathrm{D}^{2}$ and Rao 's canonical variate analysis. The twenty five inbreds fell into five distinct clusters. The intra-cluster distance in all the five clusters was more or less low, indicating the genotypes within the same clusters were closely related. The highest intercluster distance was observed between cluster I and VI and the lowest between the cluster II and III. The cluster IV and V each contained the highest number of genotypes. Cluster V showed the highest mean values for kernel yield and all the yield contributing traits except 1000-kernel weight and cluster II had the lowest mean values for plant and ear height and maturity characters. Days to silking, ear length, number of kernels/row, 1000-kernel weight and kernel yield showed maximum contribution towards total divergence among different characters. Based on medium to high inter-cluster distances, per se performances and desirable traits, fourteen yellow inbred lines viz. BIL 77, BIL 97, CML 287, CML 470, CML 480, CML 486, CZ 2370-22-2, CZ 2370-24-3, CZ 2370-28-2, CZ 23 70-31-3, IPB 911-2, IPB 911-22, IPB 911-36 and IPB 911-50 were selected for future hybridization program. Crossing between these genotypes have the chance to obtain higher heterosis with high performing crosses.
\end{abstract}

Keywords: Maize (Zea mays L.), Inbred lines, genetic divergence.

\section{Introduction}

Maize (Zea mays L.) is becoming an important cereal crop in the rice based cropping system of Bangladesh. Hybrid maize has higher yield potentiality than those of synthetics and composites. Prospective parent (inbred line) selection is a pre-requisite work for hybrid development. Several studies on maize have shown that inbred lines from diverse stocks tend to be more productive than crosses of inbred lines from the same variety (Vasal, 1998). Saxena et al. (1998) also reported that manifestation of heterosis usually depends on the genetic divergence of the two parental lines. The quantification of genetic diversity through biometrical procedure made it possible to choose genetically diverse parents

${ }^{1,2 \& 4}$ Chief Scientific Officer, Scientific Officer \& Ex-Chief Scientific Officer, Plant Breeding Division, Bangladesh Agricultural Research Institute (BARI), Gazipur, ${ }^{3}$ Principal Scientific Officer (Plant Breading), RARS, BARI, Jamalpur, Bangladesh. 
Genetic diversity is one of the useful tools to select appropriate genotypes/lines for hybridization. The genetic diversity between the genotypes is important as the genetically diverged parents are able to produce high heterotic effects (Falconer, 1960; Arunachalam, 1981; Ghaderi et al., 1984 and Mian and Bahl, 1989). Knowledge of germplasm diversity and of relationship among elite breeding materials has a significant impact on the improvement of crop plant (Hallauer et al., 1988). Maize breeders are consistently emphasizing on the importance of diversity among parental genotypes as a significant factor contributing to heterotic hybrids (Ahloowalia and Dhawan, 1963). Characterization of genetic diversity of maize germplasm is of great importance in hybrid maize breeding (Xia et al., 2005). $\mathrm{D}^{2}$ analysis is a useful tool for quantifying the degree of divergence between biological population at genotypic level and in assessing relative contribution of different components to the total divergence both at intra and inter-cluster level (Murty and Arunachalam, 1966; Ram and Panwar, 1970 and Sachan and Sharma, 1971). Therefore, the present investigation was undertaken with a view to estimate the nature and magnitude of genetic diversity of maize genotypes.

\section{Materials and Method}

Twenty five local and exotic yellow inbred lines of normal maize were grown in the field of Bangladesh Agricultural Research Institute, Joydebpur in a alpha lattice design with three replications during rabi 2009-10.The seeds of each entry were sown on 4 December 2010 in one row of $5 \mathrm{~m}$ long with spacing $25 \mathrm{x}$ $20 \mathrm{~cm}$ between rows and hills, respectively. One plant was kept per hill after proper thinning. Fertilizers were applied @ 120,80,80,20, 5 and $1 \mathrm{~kg} / \mathrm{ha}$ of N, $\mathrm{P} 2 \mathrm{OS}, \mathrm{K}_{2} 0, \mathrm{~S}, \mathrm{Zn}$ and $\mathrm{B}$, respectively. The other intercultural operations were done timely and properly to raise the crop uniformly. Observation was recorded on whole plot basis for days to pollen shedding and silking. Ten randomly selected plants were used for recording observations on kernel yield/plant (g), plant height $(\mathrm{cm})$, ear height $(\mathrm{cm})$, number of kernel rows/ear, number of kernels/row, ear length $(\mathrm{cm})$, ear diameter $(\mathrm{cm}), 1000$-kernel weight $(\mathrm{g})$, husk cover (1-5 scale) and disease reaction (1-5 scale). Genetic diversity was estimated using Mahalanabis generalized distance $\left(\mathrm{D}^{2}\right)$ extended by Rao (1952). Tocher's method was followed to determine the group constellation. Canonical variate analysis was also performed as per Rao (1964) to confirm the results of cluster $\mathrm{D}^{2}$ analysis. The data were analyzed using GENSTAT 5.0 software program. 


\section{Results and Discussion}

The mean performances of 25 yellow inbred lines are presented in Table 1 . Significant differences were observed among the lines for all the characters studied and therefore diversity analysis was carried out. The highest variability was observed in ear height followed by number of kernels/row, kernel yield/plant and ear length. Hence there is scope for selecting high yield potential lines based on the above characters.

Multivariate analysis based on Mahalanabis's $\mathrm{D}^{2}$ statistics revealed that genotypes could be grouped into five different clusters (Table 2). This suggested the presence of high degree of divergence in the material. Cluster III and V comprised maximum number of genotypes (7) followed by cluster II and cluster IV comprising 6 and 4 genotypes, respectively. The lowest single genotype was included in cluster I.

The intra- and inter cluster values among the five clusters are presented in Table 3. The inter-cluster distances were larger than the intra-cluster values. The inter-cluster distance was maximum between cluster I and V (16.93), indicating wide genetic diversity between these two clusters followed by the distance between cluster I and II (12.53), cluster IV and V (12.43), cluster I and III (10.78). The minimum inter-cluster distance was observed between cluster III and IV (6.76), followed by cluster II and V (6.01), cluster II and III (4.39), indicating that the genotypes of these clusters were genetically close (Table 3 ). The intra-cluster distance ranged from 0.6142 to 0.9285 . Comparatively, higher intra-cluster distances were observed in cluster III, cluster II and cluster V, yet they were not so far diversed from others.

The cluster mean values of all the 11 characters for each of the cluster are presented in Table 4. The data revealed that different clusters exhibited different mean values for almost all the characters. Cluster $\mathrm{V}$ was composed of seven genotypes and this cluster earned maximum mean values (Table 4) for plant height $(128 \mathrm{~cm})$, ear length $(12.4 \mathrm{~cm})$, ear height $(53 \mathrm{~cm})$, ear diameter $(4.3 \mathrm{~cm})$, number of kernels/row (27), number of kernels/ear (344) and kernel yield/plant $(69.9 \mathrm{~g})$. The genotypes of cluster I produced the lowest values for maturity traits like days to pollen shedding (87 days) and silking (90 days) and shortest plants $(93 \mathrm{~cm})$ and ear height $(34 \mathrm{~cm})$, indicating the early and dwarf genotypes in this group. This cluster also had the highest mean values for 1000-kernel weight $(260.5 \mathrm{~g})$. The genotypes of cluster II produced the highest mean values for single parameter, the number of kernel rows/ear (14). The cluster III contained 7 and cluster IV had 4 genotypes each, but none of these two clusters produced the highest mean for any traits studied. 
Table 1. Mean performances of 25 yellow inbred lines of maize evaluated at Joydebpur.

\begin{tabular}{l|c|c|c|c|c|c}
\hline \multicolumn{1}{c}{ Inbred lines } & $\begin{array}{c}\text { Days to } \\
\text { pollen } \\
\text { shedding }\end{array}$ & $\begin{array}{c}\text { Days to } \\
\text { silking }\end{array}$ & $\begin{array}{c}\text { Plant } \\
\text { height } \\
(\mathrm{cm})\end{array}$ & $\begin{array}{c}\text { Ear height } \\
(\mathrm{cm})\end{array}$ & $\begin{array}{c}\text { *Husk } \\
\text { cover }(1-5 \\
\text { scale })\end{array}$ & $\begin{array}{c}* * \text { Disease } \\
\text { TLB }(1-5 \\
\text { scale })\end{array}$ \\
\hline 1. BIL77 & 90 & 96 & 108 & 46 & 1 & 1 \\
2. BIL95 & 93 & 96 & 130 & 53 & 2 & 1 \\
3. BIL97 & 91 & 94 & 143 & 55 & 1 & 1 \\
4. BML 2 & 93 & 97 & 125 & 46 & 2 & 2 \\
5. CML197 & 89 & 93 & 116 & 49 & 2 & 1 \\
6. CML287 & 95 & 99 & 139 & 55 & 1 & 1 \\
7. CML 431 & 91 & 93 & 100 & 42 & 2 & 1 \\
8. CML 453 & 94 & 98 & 124 & 54 & 2 & 2 \\
9. CML 465 & 96 & 99 & 123 & 44 & 3 & 2 \\
10. CML 470 & 87 & 90 & 93 & 34 & 1 & 1 \\
11. CML 480 & 92 & 95 & 94 & 36 & 1 & 1 \\
12. CML 481 & 88 & 93 & 116 & 45 & 1 & 2 \\
13. CML 486 & 89 & 93 & 118 & 40 & 1 & 1 \\
14. CML 496 & 95 & 99 & 125 & 58 & 1 & 2 \\
15.CZ 2370-15-2 & 94 & 96 & 124 & 52 & 3 & 1 \\
16. CZ 2370-18-2 & 95 & 99 & 133 & 48 & 2 & 3 \\
17. CZ 2370-22-2 & 92 & 96 & 124 & 49 & 1 & 1 \\
18. CZ 2370-24-3 & 91 & 94 & 119 & 46 & 2 & 1 \\
19. CZ 2370-28-2 & 94 & 99 & 118 & 44 & 1 & 1 \\
20. CZ 2370-31-3 & 93 & 97 & 119 & 48 & 1 & 3 \\
21. IPB 911-2 & 88 & 90 & 148 & 60 & 1 & 1 \\
22. IPB 911-22 & 88 & 90 & 135 & 59 & 1 & 1 \\
23. IPB 911-36 & 93 & 97 & 112 & 43 & 1 & 1 \\
24. IPB 911-47 & 92 & 95 & 100 & 46 & 2 & 2 \\
25. IPB 911-50 & 90 & 90 & 133 & 61 & 1 & 1 \\
\hline Minimum & 88 & 91 & 93 & 34 & - & - \\
Maximum & 95 & 99 & 148 & 61 & & - \\
Mean & 91 & 95 & 120 & 48 & & - \\
F- test & $* *$ & $* *$ & $* *$ & $* *$ & - & - \\
CV (\%) & 0.60 & 0.54 & 3.13 & 7.87 & - & - \\
LSD 5\% & 1.14 & 0.99 & 7.74 & 7.75 & - & - \\
\hline
\end{tabular}

$* 1=$ excellent, $5=$ unaccepted; $* * 1=$ resistant, 5= susceptible; TLB: Turcicum leaf blight. 
Table 1. Cont'd.

\begin{tabular}{|c|c|c|c|c|c|c|c|}
\hline Inbred lines & $\begin{array}{l}\text { Ear } \\
\text { length } \\
(\mathrm{cm})\end{array}$ & $\begin{array}{c}\text { Ear dia } \\
\text { meter } \\
(\mathrm{cm})\end{array}$ & $\begin{array}{c}\text { No. of } \\
\text { kernel } \\
\text { rows/ear }\end{array}$ & $\begin{array}{c}\text { No. of } \\
\text { kernels/ } \\
\text { row }\end{array}$ & $\begin{array}{l}\text { No. of } \\
\text { kernels/ } \\
\text { ear }\end{array}$ & $\begin{array}{l}\text { 1000- } \\
\text { kernel } \\
\text { wt. (g) }\end{array}$ & $\begin{array}{c}\text { Kernel } \\
\text { yield/ } \\
\text { plant }(\mathrm{g})\end{array}$ \\
\hline 1. BIL77 & 11.9 & 3.7 & 12 & 30 & 361 & 246 & 70.0 \\
\hline 2. BIL95 & 121 & 4.0 & 12 & 25 & 296 & 233 & 61.0 \\
\hline 3. BIL97 & 11.5 & 4.1 & 12 & 24 & 275 & 256 & 72.5 \\
\hline 4. BML 2 & 11.8 & $3.7-$ & 12 & 22 & 247 & 276 & 66.0 \\
\hline 5. CML 197 & 9.7 & 3.9 & 12 & 17 & 200 & 232 & 44.0 \\
\hline 6. CML 287 & 128 & 4.2 & 12 & 30 & 359 & 255 & 73.5 \\
\hline 7. CML 431 & 10.8 & 3.9 & 12 & 22 & 266 & 226 & 58.0 \\
\hline 8. CML 453 & 9.8 & 3.7 & 12 & 21 & 250 & 242 & 51.5 \\
\hline 9. CML 465 & 10.1 & 4.1 & 12 & 21 & 250 & 247 & 57.5 \\
\hline 10. CML 470 & 10.3 & 4.0 & 12 & 19 & 224 & 260 & 51.0 \\
\hline 11. CML 480 & 10.5 & 4.2 & 14 & 22 & 294 & 228 & 63.0 \\
\hline 12. CML 481 & 9.7 & 3.8 & 14 & 20 & 268 & 222 & 58.5 \\
\hline 13. CML 486 & 112 & 4.1 & 14 & 22 & 280 & 251 & 69.5 \\
\hline 14. CML 496 & 10.8 & 4.0 & 10 & 22 & 20 & 212 & 51.0 \\
\hline 15. CZ 2370-15-2 & 122 & 4.2 & 14 & 18 & 259 & 210 & 60.5 \\
\hline 16. CZ 2370-18-2 & 10.1 & 3.6 & 10 & 22 & 198 & 232 & 48.0 \\
\hline 17. CZ 2370-22-2 & 12.7 & 4.1 & 12 & 22 & 259 & 258 & 67.5 \\
\hline 18. CZ 2370-24-3 & 12.9 & 4.1 & 14 & 23 & 312 & 258 & 66.0 \\
\hline 19. CZ 2370-28-2 & 12.7 & 4.2 & 10 & 19 & 202 & 241 & 64.0 \\
\hline 20. CZ 2370-31-3 & 10.4 & 3.8 & 12 & 22 & 255 & 231 & 62.5 \\
\hline 21. IPB 911-2 & 12.4 & 4.1 & 12 & 28 & 327 & 254 & 73.0 \\
\hline 22. IPB 911-22 & 122 & 4.2 & 14 & 27 & 361 & 238 & 72.5 \\
\hline 23. IPB 911-36 & 11.7 & 4.1 & 12 & 23 & 259 & 242 & 71.5 \\
\hline 24. IPB 911-47 & 10.8 & 3.5 & 12 & 27 & 329 & 229 & 66.5 \\
\hline 25. IPB 911-50 & 12.3 & 4.2 & 14 & 26 & 359 & 253 & 68.0 \\
\hline Minimum & 9.7 & 3.5 & 10 & 16 & 169 & 210.0 & 44.0 \\
\hline Maximum & 12.9 & 4.2 & 14 & 30 & 361 & 276.5 & 72.5 \\
\hline Mean & 11.3 & 3.9 & 12 & 23 & 274 & 242 & 62.4 \\
\hline F- test & $* *$ & $* *$ & $* *$ & $* *$ & $* *$ & $* *$ & $* *$ \\
\hline $\mathrm{CV}(\%)$ & 4.31 & 3.75 & 3.70 & 6.72 & 3.96 & 1.66 & 6.24 \\
\hline LSD $5 \%$ & 1.00 & 0.30 & 0.61 & 3.13 & 22.21 & 8.19 & 7.96 \\
\hline
\end{tabular}


Contribution of the characters towards divergence is presented in Table 5. Vector I obtained from PCA expressed that ear length, ear diameter and number of kernel rows/ear were the major characters that contribute to genetic divergence, which was the reflection of first axis of differentiation. On the contrary, the negative absolute values for vector I and positive values for vector II for the characters days to pollen shedding, plant height and number of kernels/ear indicated the responsibility of secondary differentiation. From the result it appeared that the values of both vectors (vector I and vector II) for days to silking, ear length, number of kernels/row, 1000-kernel weight and kernel yield/plant were positive. Such results indicated that these five traits contributed maximum towards diversity of genotypes. So, the greater divergence in the present materials due to these five characters will offer a good scope for improvement of yield through selection of parents.

Table 2. Distribution of 25 yellow inbred lines of maize in five clusters.

\begin{tabular}{|c|c|c|}
\hline Cluster & \begin{tabular}{c|} 
No. of \\
genotypes
\end{tabular} & Genotypes in different clusters \\
\hline I & 1 & CML 470 \\
\hline II & 6 & $\begin{array}{l}\text { BIL 95, CML 431, CML 480, CML 481, CZ 2370-15-2 and CZ } \\
\text { 2370- 31-3 }\end{array}$ \\
\hline III & 7 & $\begin{array}{l}\text { BIL 97, BML 2, CML 453, CML 465, CML 486, CZ 2370-22-2 } \\
\text { and IPB 911-36 }\end{array}$ \\
\hline IV & 4 & CML 197, CML 496, CZ 2370-18-2 and CZ 2370-28-2 \\
\hline $\mathrm{V}$ & 7 & $\begin{array}{l}\text { IPB 911-2, IPB 911-22, IPB 911-47, IPB 911-50, CZ 2370-24-3, } \\
\text { BIL } 77 \text { and CML } 287\end{array}$ \\
\hline
\end{tabular}

Table 3. Intra (bold) and inter-cluster distances of 25 yellow inbred lines of maize.

\begin{tabular}{c|c|c|c|c|c}
\hline Clusters & I & 11 & III & IV & V \\
\hline I & $\mathbf{0 . 7 3 0 1}$ & 12.53 & 10.78 & 6.90 & 16.93 \\
II & & $\mathbf{0 . 8 8 4 2}$ & 4.39 & 7.36 & 6.01 \\
III & & & $\mathbf{0 . 9 2 8 5}$ & 6.76 & 7.69 \\
IV & & & & $\mathbf{0 . 6 1 4 2}$ & 12.43 \\
V & & & & & $\mathbf{0 . 7 9 0 8}$ \\
\hline
\end{tabular}

The crosses involving parents belonging to the divergent clusters are expected to manifest maximum heterosis and also variability in genetic architecture. Mian and Bahl (1989) reported that the parents separated by D value of medium magnitude generally showed higher heterosis. Sharma (1998) reported that choice of parents based on divergence can be made for hybridization purposes. Considering these themes and agronomic performances, crosses between genotypes of cluster I with those of cluster II, III and IV are expected to improve earliness and short statured crop. Crosses between genotypes of cluster IV and V are also expected to improve the yield of maize. 
Table 4. Cluster means for 11 different characters of 25 yellow inbred lines of maize.

\begin{tabular}{l|c|c|c|c|c}
\hline \multirow{2}{*}{\multicolumn{1}{c}{ Characters }} & \multicolumn{5}{c}{ Cluster means } \\
\cline { 2 - 6 } & I & II & III & IV & V \\
\hline Days to pollen shedding & 87 & 92 & 93 & 93 & 90 \\
Days to silking & 90 & 94 & 96 & 97 & 93 \\
Plant height.(cm) & 93 & 114 & 121 & 123 & 126 \\
Ear height (cm) & 34 & 46 & 45 & 50 & 53 \\
Ear length (cm) & 10.3 & 11 & 11.3 & 10.8 & 12.4 \\
Ear diameter (cm) & 4 & 4 & 4.1 & 3.9 & 4.3 \\
No. of kernel rows/ear & 12 & 14 & 12 & 10 & 12 \\
No. of kernels/row & 16 & 21 & 22 & 20 & 27 \\
No. of kernels/ear & 169 & 273 & 260 & 205 & 344 \\
1000-kemel wt (g) & 260 & 225 & 253 & 229 & 247 \\
Kernel yield/plant (g) & 45 & 60.6 & 65.1 & 51.8 & 69.9 \\
\hline
\end{tabular}

Table 5. Relative contribution of different characters to total divergence in yellow maize inbred lines.

\begin{tabular}{lcc}
\hline \multicolumn{1}{c}{ Character } & Vector I & Vector II \\
\hline Days to pollen shedding & -0.5831 & 0.0719 \\
Days to silking & 0.5448 & 0.2766 \\
Plant height.(cm) & -0.1115 & 0.1285 \\
Ear height $(\mathrm{cm})$ & 0.2093 & -0.3224 \\
Ear length $(\mathrm{cm})$ & 0.2553 & 1.0873 \\
Ear diameter $(\mathrm{cm})$ & 6.7031 & -1.1434 \\
No. of kernel rows/ear & 1.5041 & -0.9663 \\
No. of kernels/row & 1.3566 & 0.7776 \\
No. of kernels/ear & -0.1794 & 0.0910 \\
1000-kemel weight $(\mathrm{g})$ & 0.0289 & 0.1337 \\
Kernel yield/plant $(\mathrm{g})$ & 0.0695 & 0.1912 \\
\hline
\end{tabular}

\section{Selection of parents}

Based on medium to high inter-cluster distances, per se performances and desirable traits, the fourteen yellow inbred lines viz. CML 470 from cluster I; CML 480 and CZ 2370-31-3 from cluster II; BIL 97, CML 287, CML 486, CZ 2370-22-2 and IPB 911-36 from cluster III; CZ 2370-28-2 from cluster IV and 
BIL 77, CZ 2370-24-3, IPB 911-2, IPB 911-22, IPB 911-50 from cluster V could be selected for future hybridization program.

\section{Conclusion}

The crosses between the above mentioned selected inbred lines of cluster I with those of cluster II, III and IV are expected to improve earliness and short statured crop. Crosses between genotypes of cluster IV and V are also expected to improve yield of maize. Days to pollen shedding, ear length, number of kernels/row, 1000-kernel weight and kernel yield contributed maximum towards divergence. Hence major emphasis should be given on them for selecting parents for hybridization in maize.

\section{References}

Ahloowalia, B. S. and N. I. Dhawan. 1963. Effect of genetic diversity in combining ability of inbred lines of maize. Indian J. Genet. 23: 158-162.

Arunachalam, V. 1981. Genetic distances in plant breeding. Indian J. Genet. 41: 226236.

Falconer, D. S. 1960. Introduction to Quantitative Genetics. Oliver \& Boid, London. $304 \mathrm{p}$.

Ghaderi, A., M. Shishegar, A. Regai and B. Ehdaie. 1984. Multivariate analysis of genetic diversity for yield and its components in mungbean. J. Amer. Soc. Hort. Sci. 104: 728-731.

Hallauer, A. R., W. A. Russell and K. R. Lamkey. 1988. Com breeding. In: Sprague G.F. J.W. Dudley (ed.). Corn and Corn Improvement, 3rd edn. American Society of Agronomy, Madison, WI. USA, Pp. 459-565.

Mian, M. A. K. and P. N. Bahl. 1989. Genetic divergence and hybrid performance in chickpea. Indian J. Genet. 49: 119-124.

Murty, B. R. and V. Arunachalam. 1966. The nature of divergence in relation to breeding system in crop plants. Indian J. Genet. 26A: 188-198.

Sachan, K. S. and J. R. Sharma. 1971. Multivariate analysis of divergence in tomato. Indian J. Genet. 31: 86-93.

Saxena, V. K., N. S. Mathi, N. N. Singh and S. K. Vasal. 1998. Heterosis in maize: Grouping and patterns. In: Vasal, S. K., F. C. Gonzalez and F. Xingming (ed). Proc. $7^{\text {th }}$ Asian Reg. Maize Workshop. Los Banos, Philippines. February 23-27. Pp. 124-133.

Ram, J. and D. V. S. Panwar. 1970. Interspecific divergence in rice (Oryza sativa L.). Indian J. Genet. 30: 1-2.

Rao, C. R. 1952. Advanced Statistical Methods in Biometrical Research. John Wiley and Sons, New York. 
Rao, C. R. 1964. The use and interception of principal component analysis in applied research. Sankhya, 22: 317-318.

Sharma, J. Q. 1998. Statistical and Biometrical Techniques in Plant Breeding. New Age. Intl. Pvt. Ltd., India, p. 67.

Vasal, S. K. 1998. Hybrid maize technology: Challenges and expanding possibilities for research in the next century. In: Vasal, S. K., C. F. Gonzalez and F. Xingming (ed). Proc. $7^{\text {th }}$ Asian Reg. Maize Workshop. Los Banos, Philippines, February 23-27, pp. 58-62.

Xia, X. C., J. C. Reif, A. E. Melchinger, M. Frisch, D.A. Hoisington, D. Beck, K. Pixley and M. L. Warburton. 2005. Genetic diversity among CIMMYT maize inbred lines investigated with SSR markers. Crop Sci. 45: 2573-2582. 